\title{
Validação de método para avaliação da qualidade sanitária de preparação cosmética de base lipófila
}

\author{
Nádia Araci Bou-Chacra*, Mitsuko Taba Ohara
}

Departamento de Farmácia, Faculdade de Ciências Farmacêuticas, Universidade de São Paulo

*Correspondência:

N. A. B. Chacra

Departamento de Farmácia

Faculdade de Ciências Farmacêuticas

Universidade de São Paulo

Caixa Postal 66083

05315-970 - São Paulo - SP

Brasil

E-mail: chacra@usp.br
A validação de método para a avaliação da qualidade sanitária de produto cosmético de base lipófila foi efetuada empregando-se neutralizantes químicos e diluição para a eliminação de efeito inibitório no crescimento microbiano. Para a preparação da amostra foi empregado miristato de isopropila e polissorbato 20. Além dessas substâncias, foi adicionado ao diluente $0,5 \%(p / v)$ de lecitina de soja visando à neutralização do cloreto de benzalcônio. Os ensaios foram efetuados objetivando a comprovação da ausência de efeito inibitório no crescimento microbiano decorrente de atividade antimicrobiana do produto, assim como dos agentes neutralizantes, tensoativos e solubilizante empregados no ensaio. $\mathrm{Na}$ avaliação quantitativa, os resultados demonstraram ausência de efeito inibitório no crescimento microbiano nas diluições 1:10 e 1:100. A porcentagem de microrganismos recuperados foi de, no mínimo, 93,2\% indicando a validade do método de acordo com o critério oficial adotado. Com referência ao ensaio qualitativo, foi observado efeito inibitório na diluição 1:20 para os seguintes microrganismos: Pseudomonas aeruginosa $e$ Staphylococcus aureus. Esse efeito foi eliminado empregando-se diluição 1:200, sendo, desta forma, essa diluição considerada válida para o ensaio.
Unitermos:

- Cosmético

- Qualidade sanitária

- Neutralização química

\section{INTRODUÇÃO}

Na avaliação da qualidade sanitária de produtos farmacêuticos e cosméticos, a fim de comprovar a conformidade ou não com especificações microbiológicas, os métodos analíticos devem ser validados. A validação assegura a confiabilidade nos resultados obtidos quando amostras são analisadas.

Os métodos para a avaliação da qualidade sanitária de medicamentos e cosméticos consistem na determinação do número de microrganismos viáveis e na pesquisa de microrganismos patogênicos específicos. As etapas para a avaliação quantitativa são: preparação da amostra, seleção do método de contagem, incubação a temperatura e tempo adequados e leitura do ensaio objetivando a determinação do número de colônias, quando em meio sólido, ou a visualização de turvação, em meio líquido. A avaliação qualitativa inclui as etapas de enriquecimento em meio não-seletivo, enriquecimento e isolamento em meios seletivos. Nos casos de crescimento característico nos meios de isolamento seletivo, efetua-se a identificação do contaminante (FB, 1988; USP, 2002; BP, 1999). Con- 
seqüentemente, a validação do método deve abranger todas as etapas do ensaio.

Os ensaios para a avaliação da qualidade sanitária foram descritos, pela primeira vez, em 1942, na Farmacopéia Americana XII edição, para a determinação de bactérias e pesquisa de Escherichia coli em gelatina. No entanto, preocupação relativa à inibição do crescimento microbiano decorrente da presença de substâncias antimicrobianas incorporadas ao produto foi mencionada somente após 33 anos, na XIX edição (1975) desse compêndio. A partir dessa edição foi recomendado o emprego de diluição adequada, da adição de quantidade suficiente de agentes neutralizantes, ou, ainda, da utilização do recurso de filtração para eliminar o efeito inibitório do produto nos ensaios e essas orientações permaneceram inalteradas até sua XXIII edição (1995). Essas edições não mencionavam quaisquer orientações relativas à condução do ensaio ou aos critérios de aceitação para a comprovação da eficácia dos recursos adotados. Tampouco referiam-se à avaliação da toxicidade decorrente dos neutralizantes empregados ou de sua combinação com outros componentes da formulação. Esses compêndios mencionavam apenas a adição de lecitina de soja a $0,5 \%$ (p/v) e polissorbato 20 a $4 \%$ (p/v) nos meios de cultura para neutralizar possíveis substâncias inibitórias presentes na amostra.

Nas duas últimas edições (USP, 2000; USP, 2002), a Farmacopéia Americana dedicou capítulo exclusivo para a validação de métodos microbiológicos, visando fundamentalmente à comprovação da eficácia do método na recuperação dos contaminantes do produto. Nesse sentido, tais compêndios recomendam a inclusão de bactérias gramnegativa e gram-positiva, além de bolor e levedura, porém não especificam quais microrganismos devem ser empregados. Com referência à concentração de células, esses compêndios recomendam utilização de carga inferior a 100 $\mathrm{UFC} / \mathrm{mL}$ ou g da amostra, de forma que o método proposto apresente sensibilidade adequada para a detecção de baixa carga microbiana. Os métodos para neutralizar as propriedades antimicrobianas de produtos são os mesmos descritos nos compêndios anteriores: neutralização por inativação química; neutralização por diluição e filtração com subseqüente lavagem da membrana filtrante, podendo ser utilizada a associação dos métodos propostos. No entanto, diversos neutralizantes foram indicados e correlacionados com a respectiva classe do biocida incorporado ao produto, orientando a especificidade da reação de neutralização. O polissorbato e a lecitina foram indicados para substâncias antimicrobianas específicas como os parabenos e os amônios quaternários. Com referência à toxicidade dos neutralizantes, sua inocuidade deve ser comprovada evitando, desta forma, resultado falso-negativo no ensaio. O cri- tério de aceitação adotado fundamenta-se na porcentagem de recuperação (não inferior a 70\%) de microrganismos ou análise estatística.

A seleção da filtração como recurso para a eliminação de efeito inibitório no método de avaliação do produto apresenta limitação relativa às características do produto. Esse recurso permite a retenção das células na membrana filtrante e requer o emprego de fluido de lavagem adequado, no geral, solução aquosa contendo $0,1 \%(\mathrm{p} / \mathrm{v})$ de peptona para a eliminação de resíduo de agentes antimicrobianos da membrana. No que se refere à diluição, o objetivo consiste na redução dos agentes antimicrobianos incorporados ao produto de forma a alcançar concentração inferior à mínima inibitória. Porém, o número de diluições decimais seriadas efetuadas não deverá comprometer a sensibilidade do método, vinculada à especificação do produto, ou seja $<1000 \mathrm{UFC} / \mathrm{mL}$ para produtos cosméticos risco 1 (Brasil, Resolução RDC n 481, 1999). Com relação à inativação química, as substâncias incorporadas no meio de cultura e/ou diluente deverão ser selecionadas em função de sua ação neutralizadora específica e, como mencionado anteriormente, sua inocuidade deverá ser comprovada.

No que se refere ao compêndio britânico, a orientação relativa à validação de métodos microbiológicos para a avaliação da qualidade sanitária de produtos farmacêuticos foi descrita, pela primeira vez, no addendum de 1986 da Farmacopéia Britânica de 1980. O compêndio menciona os mesmos recursos descritos no compêndio americano para eliminar qualquer propriedade antimicrobiana do produto a ser examinado. Além de orientações relativas a esses recursos, o compêndio indica quais microrganismos devem ser empregados, suas concentrações (cerca de 100 $\mathrm{UFC} / \mathrm{mL}$ ou g da amostra) no ensaio assim como a utilização de cepas de referência isoladas de Staphylococcus aureus, esporos de Bacillus subtilis, Escherichia coli e Candida albicans. O critério de aceitação adotado menciona que a diferença entre o ensaio e o controle não deve exceder de fator igual a 10 . As edições posteriores, de 1988 e 1993, permaneceram inalteradas e harmonizadas com a Farmacopéia Européia $3^{\circ}$ edição (EP, 1996). A partir de 1999, o critério de aceitação relativo ao compêndio britânico foi alterado para diferença não maior que fator de 5 entre o ensaio e o controle, indicando maior exigência com relação à interpretação dos resultados quando comparado aos compêndios anteriores. Além da alteração referente ao critério de interpretação dos resultados, o compêndio incluiu cepa de Aspergilllus niger na lista de microrganismos desafiantes e apresentou tabela orientando o emprego de agente neutralizante específico para cada classe de antimicrobiano. A Farmacopéia Européia $3^{\circ}$ 
edição (1996) efetuou as mesmas alterações, mantendo a harmonização entre os compêndios.

A quarta edição da Farmacopéia Brasileira (1988) incluiu os ensaios para avaliação da qualidade sanitária de produtos adotando parte da orientação descrita no addendum de 1986 da Farmacopéia Britânica de 1980. Tais orientações referem-se aos recursos para a eliminação do efeito inibitório do produto, à condução do ensaio, ao emprego de cepas isoladas e suas concentrações (100 $\mathrm{UFC} / \mathrm{mL}$ ). No entanto, o critério de interpretação dos resultados obtidos não foi apresentado, de forma similar ao compêndio americano em suas edições anteriores a XXIV (2000). De forma similar a esses compêndios, a associação de polissorbato e lecitina é recomendada para a neutralização do efeito inibitório do produto. Porém, o compêndio nacional indica a utilização de polissorbato 80 em substituição ao polissorbato 20 preconizado pelo compêndio americano e com concentração 10 vezes inferior $(0,4 \% \mathrm{p} / \mathrm{v})$.

De forma contrastante às recomendações oficiais que orientam a utilização de cepas isoladas, o CTFA (Curry, Graf, McEwen, 2001) recomenda o emprego de 4 diferentes culturas mistas: bactérias gram-positivas, bactérias gram-negativas, leveduras e bolores para avaliar a neutralização do efeito inibitório do produto. Os recursos propostos, assim como a concentração de células para a execução do ensaio, são semelhantes aos compêndios oficiais. Porém, o critério de interpretação dos resultados limita-se à observação da turvação ou não do crescimento microbiano.

A precisão dos métodos de detecção de microrganismos viáveis, utilizando meios de cultura, depende fundamentalmente da preparação da amostra. Os eventuais contaminantes presentes deverão estar em contato íntimo com o meio de cultura, possibilitando o acesso aos nutrientes. Desta forma, os procedimentos para a preparação da amostra são de fundamental importância. Tais procedimentos dependem da sua natureza, a fim de compatibilizálos com a técnica de contagem selecionada. O tratamento a ser empregado tem por finalidade obter soluções, dispersões ou suspensões e que, por sua vez, não alterem o número e as características dos microrganismos originalmente presentes (USP, 2002).

Produtos de base lipófila apresentam limitações para a aplicação dos métodos de avaliação, pois estes requerem a compatibilização da amostra com meios de cultura que são aquosos. A avaliação da qualidade sanitária para esses produtos requer a preparação da amostra, de forma a resultar em mistura homogênea quando diluída em fluidos aquosos. Para isto, necessitam de recursos auxiliares como adição de tensoativos, de solventes orgânicos ou de aque- cimento e, dependendo das características da amostra, há necessidade de diferentes concentrações dessas substâncias incluindo a sua associação. A Farmacopéia Brasileira (1988), de forma semelhante ao compêndio britânico, classifica a preparação das amostras em substâncias solúveis em água, substâncias oleosas miscíveis em água e substâncias solúveis em miristato de isopropila. Esses procedimentos podem provocar alguma ação deletéria nos microrganismos presentes na amostra. Conseqüentemente, a validação é de fundamental importância para assegurar a viabilidade dos microrganismos.

Limitação adicional refere-se à técnica de semeadura em profundidade para avaliação de amostras de base lipófila. Esse método ocasiona a opalescência do meio de cultura, dificultando a observação de colônias. A utilização do cloreto de trifeniltetrazólio promove a coloração das colônias para vermelho, facilitando a contagem, sem, no entanto, comprometer a viabilidade das células no caso de sua adição após o período de incubação (Ohara, Saito, 1993; Ohara, Saito, 1995).

O objetivo do presente trabalho foi validar método para avaliação da qualidade sanitária de cosmético com base lipófila.

\section{MATERIAIS E MÉTODOS}

\section{Materiais}

O material, objeto do presente estudo, foi constituído de produto cosmético de base lipófila contendo cloreto de benzalcônio.

\section{Métodos}

\section{Validação do Método de Determinação do Número de Microrganismos Viáveis por Semeadura em Profundidade}

- Obtenção e Padronização de Suspensão Microbiana

Transferiu-se para cada tubo contendo ágar caseínasoja inclinado cepa de Staphylococcus aureus ATCC 6538, Pseudomonas aeruginosa ATCC 9027 e Escherichia coli ATCC 8739 proveniente de cultura estoque. Após 24 horas de incubação a $32 \pm 2,5^{\circ} \mathrm{C}$, a massa celular obtida foi recolhida empregando $9 \mathrm{~mL}$ de solução de cloreto de sódio a $0,85 \%(\mathrm{p} / \mathrm{v})$. Para os fungos, o meio utilizado foi o ágar Sabouraud-dextrose e incubação a 22 $\pm 2,5{ }^{\circ} \mathrm{C}$ durante 48 horas para Candida albicans ATCC 10231 e 7 dias para o Aspergillus niger ATCC 16404. Empregou-se solução de cloreto de sódio a 0,85\% (p/v) 
acrescida de $0,05 \%(\mathrm{p} / \mathrm{v})$ de polissorbato 20 e pérolas de vidro para a remoção dos esporos de Aspergillus niger. A contagem das suspensões microbianas foi efetuada empregando para a diluição, solução de cloreto de sódio a $0,85 \%$ $(\mathrm{p} / \mathrm{v})$. Alíquota de $1 \mathrm{~mL}$ das diluições foi transferida, em duplicata, para placa de petri e homogeneizada com cerca de $15 \mathrm{~mL}$ de ágar caseína-soja e ágar Sabourauddextrose, respectivamente para bactérias e fungos. As placas foram incubadas a $32 \pm 2,5^{\circ} \mathrm{C}$ por 48 horas para as bactérias e a $22 \pm 2,5^{\circ} \mathrm{C}$ por período de 72 horas e de 96 horas, respectivamente para a levedura e para o bolor. Após a determinação do número de viáveis, cada suspensão microbiana, mantida sob refrigeração, foi submetida a diluições decimais seriadas de forma a se obter concentração de célula inferior a $100 \mathrm{UFC} / \mathrm{mL}$.

\section{- Preparação da Amostra}

Alíquota de $5 \mathrm{~mL}$ de miristato de isopropila esterilizada por filtração em membrana de éster de celulose porosidade nominal de $0,22 \mathrm{~mm}$ foi transferida para béquer contendo $5 \mathrm{~g}$ da amostra e procedeu-se à homogeneização empregando bastão de vidro. A mistura foi transferida para tubo contendo $40 \mathrm{~mL}$ de solução de cloreto de sódio a $0,85 \%(\mathrm{p} / \mathrm{v})$ acrescida de $4 \%$ de polissorbato 20 (diluição 1:10). A dispersão foi agitada vigorosamente empregando agitador tipo vortex por 1 minuto. Esse procedimento foi repetido em intervalos de 5 minutos, por 20 minutos, totalizando 4 minutos de agitação. Transferiram-se $5 \mathrm{~mL}$ da diluição $1: 10$ para erlenmeyer contendo $45 \mathrm{~mL}$ do diluente de forma a se obter a diluição 1:100. A homogeneização foi efetuada por meio de agitação vigorosa manual por 20 segundos.

- Avaliação da Atividade Inibitória dos Agentes Neutralizantes Adicionados aos Meios de Cultura

Ensaios controles foram realizados em paralelo transferindo-se $0,5 \mathrm{~mL}$ de cada suspensão microbiana, em triplicata, adicionando-se ágar caseína-soja contendo $4 \%$ $(\mathrm{p} / \mathrm{v})$ de polissorbato 20 e $0,5 \%$ (p/v) de lecitina de soja, para bactérias e ágar Sabouraud-dextrose contendo 4\% (p/v) de polissorbato 20 e $0,5 \%$ (p/v) de lecitina de soja, para fungos. $\mathrm{O}$ mesmo ensaio foi realizado empregado os meios de cultura isentos dos agentes neutralizantes. As placas foram incubadas a $32,5 \pm 2,5^{\circ} \mathrm{C}$, por 48 horas, para bactérias e a $22,5 \pm 2,5^{\circ} \mathrm{C}$, por período de 5 dias, para os fungos.

- Avaliação da Atividade Inibitória do Diluente

Transferiu-se $1 \mathrm{~mL}$ do diluente empregado, solução salina a $0,85 \%(\mathrm{p} / \mathrm{v})$ acrescido de $4 \%(\mathrm{p} / \mathrm{v})$ de polissorbato 20 , e $0,5 \mathrm{~mL}$ de cada suspensão de microrganismo contendo cerca de 100 unidades formadoras de colônia (UFC/ $\mathrm{mL}$ ). Homogeneizaram-se as alíquotas empregando-se, para bactérias, ágar caseína-soja contendo $4 \%(\mathrm{p} / \mathrm{v})$ de polissorbato 20 e $0,5 \%(\mathrm{p} / \mathrm{v})$ de lecitina de soja e, para fungos, ágar Sabouraud-dextrose contendo 4\% (p/v) de polissorbato 20 e $0,5 \%(\mathrm{p} / \mathrm{v})$ de lecitina de soja. Os ensaios foram realizados para cada microrganismo, isoladamente, em triplicata. O mesmo procedimento foi utilizado empregando ágar caseína-soja e ágar Sabouraud-dextrose isento dos agentes inativantes (polissorbato e lecitina). As placas foram incubadas a $32,5 \pm 2,5^{\circ} \mathrm{C}$, por 48 horas, para bactérias e a $22,5 \pm 2,5^{\circ} \mathrm{C}$, por 5 dias, para os fungos.

- Avaliação da Atividade Inibitória do Miristato de Isopropila

Efetuou-se a esterilização do miristato de isopropila empregando-se dois distintos processos: autoclavação a $121{ }^{\circ} \mathrm{C}$ por 15 minutos e por filtração em membrana porosidade $0,22 \mathrm{~mm}$. A avaliação da atividade antimicrobiana do miristato de isopropila esterilizado por ambos os processos foi efetuado da seguinte forma: transferiu-se $0,5 \mathrm{~mL}$ do miristato de isopropila e $0,5 \mathrm{~mL}$ de cada suspensão de microrganismo contendo cerca de $100 \mathrm{UFC} / \mathrm{mL}$, isoladamente (Staphylococcus aureus, Pseudomonas aeruginosa, Escherichia coli, Candida albicans e Aspergillus niger). Homogeneizaram-se as alíquotas empregando-se, para bactéria, ágar caseína-soja contendo 4\% $(\mathrm{p} / \mathrm{v})$ de polissorbato 20 e $0,5 \%(\mathrm{p} / \mathrm{v})$ de lecitina de soja e, para fungos, ágar Sabouraud-dextrose contendo 4\% (p/v) de polissorbato 20 e $0,5 \%(\mathrm{p} / \mathrm{v})$ de lecitina de soja. O mesmo procedimento foi utilizado empregando-se ágar caseína-soja e ágar Sabouraud-dextrose isento dos agentes inativantes. Os ensaios foram realizados para cada microrganismo, isoladamente, em triplicata. As placas foram incubadas a $32,5 \pm 2,5^{\circ} \mathrm{C}$, por 48 horas, para bactérias e a $22,5 \pm 2,5^{\circ} \mathrm{C}$, por 5 dias, para os fungos.

\section{- Avaliação da Atividade Inibitória do Produto}

Transferiu-se para placa de petri alíquota de $1 \mathrm{~mL}$ da diluição 1:10 e 0,5 mL da suspensão microbiana padronizada contendo concentração inferior a $100 \mathrm{UFC} / \mathrm{mL}$. O mesmo procedimento foi efetuado empregando-se a diluição 1:100 do produto. Os ensaios foram realizados para cada microrganismo isoladamente e em triplicata. As alíquotas foram homogeneizadas empregando-se $15 \mathrm{~mL}$ de ágar caseína-soja contendo $4 \%(\mathrm{p} / \mathrm{v})$ de polissorbato $20 \mathrm{e}$ $0,5 \%(\mathrm{p} / \mathrm{v})$ de lecitina de soja, para os ensaios com bacté- 
rias. O mesmo procedimento foi realizado para os fungos empregando-se ágar Sabouraud-dextrose contendo 4\% $(\mathrm{p} / \mathrm{v})$ de polissorbato 20 e $0,5 \%(\mathrm{p} / \mathrm{v})$ de lecitina de soja. As placas foram incubadas a $32,5 \pm 2,5^{\circ} \mathrm{C}$, por 48 horas, para bactérias e a $22,5 \pm 2,5^{\circ} \mathrm{C}$, por 5 dias, para os fungos. Após incubação foi transferida quantidade igual a $5 \mathrm{~mL}$ de ágar-ágar acrescido de $0,1 \%(\mathrm{p} / \mathrm{v})$ de TTC (cloreto de trifeniltetrazólio) para as placas relativas aos ensaios para bactérias e levedura. As placas foram reincubadas por 60 minutos antes da leitura empregando a mesma temperatura de incubação.

\section{Validação do Método de Pesquisa de Patogênicos Específicos}

\section{- Preparação da Amostra}

Porção de $5 \mathrm{~g}$ da amostra foi transferida para béquer contendo $5 \mathrm{~mL}$ de miristato de isopropila e procedeu-se à homogeneização empregando-se bastão de vidro. A mistura foi transferida para tubo contendo $90 \mathrm{~mL}$ de caldo caseína-soja, acrescido de $4 \%$ de polissorbato 20 e $0,5 \%$ $(\mathrm{p} / \mathrm{v})$ de lecitina de soja (diluição 1:20). A dispersão foi homogeneizada empregando agitador tipo vortex por 1 minuto. Esse procedimento foi repetido em intervalos de 5 minutos, por 20 minutos. Transferiu-se alíquota de 10 $\mathrm{mL}$ desta dispersão para tubo contendo $90 \mathrm{~mL}$ de caldo caseína soja adicionado dos inativantes citados anteriormente, obtendo-se a diluição 1:200. O mesmo procedimento foi realizado empregando-se caldo lactosado contendo $4 \%$ de polissorbato 20 e $0,5 \%(\mathrm{p} / \mathrm{v})$ de lecitina de soja.

\section{- Enriquecimento em Meio Não-Seletivo}

Adicionou-se às amostras diluídas (1:20 e 1:200) em caldo caseína-soja contendo $4 \%$ de polissorbato 20 e $0,5 \%$ $(\mathrm{p} / \mathrm{v})$ de lecitina de soja - preparadas conforme item Preparação da Amostra - 0,5 mL de suspensão microbiana com cerca de $100 \mathrm{UFC} / \mathrm{mL}$ de Pseudomonas aeruginosa e 0,5 $\mathrm{mL}$ contendo cerca de $100 \mathrm{UFC} / \mathrm{mL}$ de Staphylococcus aureus, padronizada conforme item Obtenção e Padronização da Suspensão Microbiana. Após homogeneização empregando-se agitação manual por 10 segundos, os tubos foram incubados a $32,5 \pm 2,5^{\circ} \mathrm{C}$, por 48 horas. $\mathrm{O}$ mesmo procedimento foi realizado empregando-se as diluições da amostra em caldo lactosado contendo $4 \%(\mathrm{p} / \mathrm{v})$ de polissorbato 20 e $0,5 \%(\mathrm{p} / \mathrm{v})$ de lecitina de soja. Adicionouse a esse tubo $0,5 \mathrm{~mL}$ de suspensão contendo cerca de 100 UFC/mL de Escherichia coli e, após homogeneização, os tubos foram incubados a $32,5 \pm 2,5^{\circ} \mathrm{C}$, por 48 horas.

\section{• Enriquecimento em Meio Não-Seletivo}

Em tubos contendo $95 \mathrm{~mL}$ de caldo caseína-soja acrescido de $4 \%(\mathrm{p} / \mathrm{v})$ de polissorbato 20 e $0,5 \%(\mathrm{p} / \mathrm{v})$ de lecitina de soja foram adicionados $0,5 \mathrm{ml}$ de suspensão com 100 UFC de Staphylococcus aureus e Pseudomonas aeruginosa preparada conforme item Obtenção e Padronização da Suspensão Microbiana. O mesmo procedimento foi efetuado empregando-se tubo com $95 \mathrm{~mL}$ de caldo lactosado contendo $4 \%(\mathrm{p} / \mathrm{v})$ de polissorbato 20 e $0,5 \%(\mathrm{p} /$ v) de lecitina de soja, transferindo-se suspensão com 100 UFC/mL de Escherichia coli. Após homogeneização, os tubos foram incubados a $32,5 \pm 2,5^{\circ} \mathrm{C}$, por 48 horas.

\section{- Isolamento em Meio Seletivo}

Após incubação, foi efetuada, com o auxílio de alça de Henle, a semeadura em estria de alíquotas obtidas do enriquecimento em meio não seletivo (item Enriquecimento em Meio Não-Seletivo) nos seguintes meios seletivos: ágar Mac Conkey, ágar Cetrimida, ágar Vogel Johnson, preparados de acordo com a recomendação do fabricante (Difco ${ }^{\circledR}$ ) respectivamente para a pesquisa de Escherichia coli, Pseudomonas aeruginosa e Staphylococcus aureus. As placas foram incubadas por período de 24 horas a $32,5 \pm 2,5^{\circ} \mathrm{C}$.

- Comprovação da Capacidade Promotora dos Meios de Cultura Empregados no Isolamento em Meio Seletivo

Transferiu-se, empregando-se técnica por esgotamento e com o auxílio de alça de Henle, para placa de petri contendo ágar MacConkey, ágar Cetrimida e ágar Vogel Johnson, respectivamente os seguintes microrganismos: Escherichia coli, Pseudomonas aeruginosa e Staphylococcus aureus. As placas foram incubadas por período de 24 horas a $32,5 \pm 2,5^{\circ} \mathrm{C}$.

\section{Determinação da Carga Microbiana Viável da Amostra}

Efetuou-se em paralelo contagem de bactérias aeróbias mesófilas viáveis do produto transferindo-se alíquota de $1 \mathrm{~mL}$ do produto diluído conforme item Preparação da Amostra (1:10 e 1:100), em triplicata, para placa de petri. A alíquota foi homogeneizada com ágar caseína-soja contendo $4 \%(\mathrm{p} / \mathrm{v})$ de polissorbato 20 e $0,5 \%$ $(\mathrm{p} / \mathrm{v})$ de lecitina de soja. Para a contagem de fungos empregou-se ágar Sabouraud-dextrose contendo as mesmas concentrações dos inativantes. Após incubação, foi transferida quantidade igual a $5 \mathrm{~mL}$ de ágar-ágar $(1,5 \% \mathrm{p} / \mathrm{v})$ 
acrescido de $0,1 \%(\mathrm{p} / \mathrm{v})$ de TTC (cloreto de trifeniltetrazólio) para as placas. As placas foram reincubadas a $32,5 \pm 2,5^{\circ} \mathrm{C}$ por 60 minutos antes da leitura.

\section{Comprovação da Ausência de Microrganismos Viáveis no Miristato de Isopropila}

A esterilidade - comprovação da ausência de microrganismos viáveis - do miristato de isopropila empregado como adjuvante na homogeneização da amostra foi realizada empregando-se método por filtração em membrana de éster de celulose porosidade nominal de 0,45 $\mathrm{mm}$. Após fracionamento da membrana obtendo-se duas metades, essas foram transferidas para tubos contendo respectivamente $100 \mathrm{~mL}$ de Meio Fluido de Tioglicolato e Caldo Caseína-soja. Os tubos foram incubados a 32,5 \pm $2,5^{\circ} \mathrm{C}$, para bactérias e a $22,5 \pm 2,5^{\circ} \mathrm{C}$, para os fungos, por período de 14 dias.

\section{RESULTADOS}

O resultado do teste de esterilidade relativo ao miristato de isopropila revelou ausência de microrganismos viáveis no método adotado. Com referência à determinação do número de microrganismos viáveis presentes na amostra foi detectada quantidade inferior a $10 \mathrm{UFC} / \mathrm{g}$.

Os meios empregados para a pesquisa de microrganismos patogênicos específicos comprovaram sua capacidade promotora do crescimento microbiano nas condições do ensaio.

\section{DISCUSSÃO}

A inibição do crescimento microbiano decorrente do efeito bacteriostático ou fungistático da formulação pode ocasionar resultado falso-negativo nas técnicas de contagem microbiana, dependentes da formação de colônias ou da presença de turvação para a detecção de contaminantes.

No presente trabalho foram adotados dois recursos distintos para a neutralização do sistema conservante: a diluição e a adição, ao meio de cultura, de substâncias inativantes específicas: $4 \%(\mathrm{p} / \mathrm{v})$ de polissorbato 20 e $0,5 \%(\mathrm{p} / \mathrm{v})$ de lecitina de soja, visando à neutralização química do cloreto de benzalcônio. A seleção dos inativantes específicos foi efetuada considerando sua ampla aplicação e facilidade de dispersão no meio de cultura. Singer (1987) relatou que esses agentes não devem ter efeito inibitório no crescimento microbiano, proveniente de si próprio ou de sua combinação com o sistema conservante, e sua ação deve ser rápida pois neutralização lenta ainda permitirá efeito biocida no decorrer do período de incubação, na etapa de quantificação dos sobreviventes. Kohn, Gershenfeld e Barr (1963) relataram a utilização de polissorbato 80 a 3\% (p/v) e lecitina de soja a $0,5 \%(\mathrm{p} / \mathrm{v})$ para a neutralização de cloreto de benzalcônio em produto oftálmico. Da mesma forma, Davison et al. (1991) avaliaram a adição de $3 \%(\mathrm{p} / \mathrm{v})$ de polissorbato 80 ao diluente para a neutralização do amônio quaternário. Em ambos os casos comprovou-se a inativação do conservante e a ausência de efeito deletério decorrente desse agente ou de sua combinação com outros componentes da fórmula. Conforme apresentado nas Tabelas I e II, os resultados relativos ao presente estudo evidenciaram a ausência de efeito inibitório dos agentes incorporados ao meio de cultura e diluente empregados, assim como sua associação. Os índices de recuperação dos microrganismos em relação ao ensaio controle foram superiores a $92,0 \%$. Índices superiores a $100 \%$, observados nas Tabelas I e II, podem ser atribuídos à variabilidade, inerente à técnica. De acordo com o compêndio oficial, recuperação igual ou superior a $70 \%$ das células empregadas para o ensaio indicam a ausência de atividade antimicrobiana dos agentes neutralizantes empregados. Para a dispersão do produto de caráter lipófilo em diluente aquoso foi utiliza-

TABELA I - Avaliação da atividade inibitória dos agentes neutralizantes (4\% de polissorbato 20 (p/v) e $0,5 \%$ de lecitina de soja $(\mathrm{p} / \mathrm{v}))$ na promoção de crescimento microbiano pelos meios de cultura

\begin{tabular}{lccccc}
\hline Microrganismos & \multicolumn{2}{c}{ Controle } & Meio de Cultura & \\
& Réplicas* & Média** & Réplicas* & Média** & R\% \\
\hline Staphylococcus aureus & $51 / 48 / 46$ & 48 & $50 / 49 / 48$ & 49 & 102,1 \\
Pseudomonas aeruginosa & $42 / 41 / 43$ & 42 & $42 / 42 / 41$ & 42 & 100,0 \\
Escherichia coli & $41 / 46 / 48$ & 45 & $45 / 47 / 49$ & 47 & 104,4 \\
Candida albicans & $53 / 51 / 53$ & 52 & $53 / 51 / 56$ & 53 & 101,9 \\
Aspergillus niger & $27 / 29 / 26$ & 27 & $26 / 28 / 27$ & 27 & 100,0 \\
\hline
\end{tabular}

* $\mathrm{N}^{\circ}$ unidades formadoras de colônia (UFC) por placa; ** Média das triplicatas (UFC); R\%: porcentagem de recuperação. 
TABELA II - Avaliação da atividade inibitória do diluente da amostra (Solução salina $0,85 \%$ (p/v) com $4 \%$ de polissorbato $20(\mathrm{p} / \mathrm{v}))$ sobre o crescimento de microrganismos testes em meios de cultura adicionados ou não de $4 \%$ de polissorbato $20(\mathrm{p} / \mathrm{v})$ e $0,5 \%$ de lecitina de soja $(\mathrm{p} / \mathrm{v})$

\begin{tabular}{lccccrrrr}
\multirow{2}{*}{ Microrganismos } & \multicolumn{2}{c}{ Controle } & \multicolumn{3}{c}{ dos tensoativos } & \multicolumn{3}{c}{ contendo tensoativos } \\
& Réplicas* & Média** & Réplicas* & Média** & R\% & Réplicas* & Média** & R\% \\
\hline Staphylococcus aureus & $51 / 48 / 46$ & 48 & $49 / 47 / 48$ & 48 & 100,0 & $55 / 50 / 43$ & 49 & 102,1 \\
Pseudomonas aeruginosa & $42 / 41 / 43$ & 42 & $38 / 40 / 38$ & 39 & 92,9 & $40 / 41 / 45$ & 42 & 100,0 \\
Escherichia coli & $41 / 46 / 48$ & 45 & $44 / 44 / 48$ & 45 & 100,0 & $44 / 47 / 42$ & 44 & 97,8 \\
Candida albicans & $53 / 51 / 53$ & 52 & $47 / 50 / 55$ & 51 & 98,1 & $55 / 50 / 50$ & 52 & 100,0 \\
Aspergillus niger & $27 / 29 / 26$ & 27 & $27 / 22 / 29$ & 26 & 96,3 & $23 / 25 / 26$ & 25 & 92,6 \\
\hline
\end{tabular}

$* \mathrm{~N}^{\circ}$ unidades formadoras de colônia (UFC) por placa; ** Média das triplicatas (UFC); R\%: porcentagem de recuperação.

do o solvente, miristato de isopropila. Entretanto, a utilização desse solvente deve ser efetuada com critério, uma vez que apresenta toxicidade para os microrganismos. A toxicidade desse solvente está relacionada com o seu processo de purificação e esterilização. A presença de substâncias ácidas diminui o valor $\mathrm{D}$, tempo de redução decimal de sobrevivência de microrganismos (Ringertz, Ringertz, 1982). A esterilização térmica eleva a quantidade de substâncias ácidas, quando comparada à esterilização por filtração em membrana (Robertson, 1974; Bowman et al., 1972; Tsuji, Robertson, 1970). Os resultados evidenciaram a ausência de atividade inibitória do miristato de isopropila sobre os microrganismos empregados no ensaio (Tabelas III e IV). Os índices de recuperação das células referentes ao ensaio empregando miristato de isopropila foram respectivamente 93,8 e $85,4 \%$ para o processo de esterilização por filtração em membrana e autoclavação. Apesar de menor recuperação relativa ao processo térmico, ambos os métodos podem ser conside- rados válidos de acordo com o compêndio oficial adotado. Os resultados dos testes de esterilidade demonstraram a eficiência dos processos de esterilização empregados.

Considerando a não interferência das substâncias neutralizadoras, assim como do agente tensoativo e solvente empregados no crescimento microbiano, a comprovação da ausência da atividade inibitória do produto no método de contagem adotado pode ser constatada na Tabela $\mathrm{V}$, para as diluições 1:10 e 1:100, para todos os microrganismos empregados. Os índices de recuperação observados foram, no mínimo, de 93,2\%, assegurando, desta forma, a validade do método adotado. Com referência à avaliação qualitativa, os resultados apresentados indicaram crescimento atípico quando comparado ao controle (Tabela VII) e ausência de crescimento microbiano respectivamente para Pseudomonas aeruginosa e Staphylococcus aureus, para a diluição 1:20, conforme Tabela VI. A inibição do crescimento microbiano foi eliminada no ensaio empregando-se a diluição 1:200, indi-

TABELA III - Avaliação da atividade inibitória do miristato de isopropila, esterilizado por filtração em membrana, sobre o crescimento de microrganismos testes em meios de cultura adicionados ou não de $4 \%$ (p/v) de polissorbato 20 e $0,5 \%$ $(\mathrm{p} / \mathrm{v})$ de lecitina de soja

\section{Microrganismos}

\begin{tabular}{|c|c|c|}
\hline & Réplicas* & Média** \\
\hline$\overline{\text { Staphylococcus aureus }}$ & $67 / 61 / 59$ & 62 \\
\hline Pseudomonas aeruginosa & $45 / 51 / 49$ & 48 \\
\hline Escherichia coli & $55 / 55 / 59$ & 56 \\
\hline Candida albicans & $76 / 78 / 73$ & 76 \\
\hline Aspergillus niger & $34 / 29 / 31$ & 31 \\
\hline
\end{tabular}

\section{Meio de Cultura isento dos tensoativos}

Réplicas* Média** R\%

$65 / 60 / 63$

$42 / 49 / 45$

$63 \quad 101,6$

$52 / 57 / 53$

$77 / 73 / 75$

$33 / 30 / 31$

\section{Meio de Cultura contendo tensoativos} Réplicas* Média** R\%

$\begin{array}{lll}62 / 60 / 61 & 61 & 98,4 \\ 50 / 43 / 45 & 46 & 95,8 \\ 51 / 56 / 52 & 53 & 94,6 \\ 73 / 73 / 77 & 74 & 97,4 \\ 30 / 30 / 31 & 30 & 96,8\end{array}$

* $\mathrm{N}^{\circ}$ unidades formadoras de colônia (UFC) por placa; ** Média das triplicatas (UFC); R\%: porcentagem de recuperação. 
TABELA IV - Avaliação da atividade inibitória do miristato de isopropila, esterilizado por autoclavação, sobre o crescimento de microrganismos testes em meios de cultura adicionados ou não de $4 \%$ (p/v) de polissorbato 20 e $0,5 \%$ $(\mathrm{p} / \mathrm{v})$ de lecitina de soja

\begin{tabular}{|c|c|c|c|c|c|c|c|c|}
\hline \multirow[t]{2}{*}{ Microrganismos } & \multicolumn{2}{|c|}{ Controle } & \multicolumn{3}{|c|}{ dos tensoativos } & \multicolumn{3}{|c|}{ contendo tensoativos } \\
\hline & Réplicas* & Média** & Réplicas* & Média** & $\mathrm{R} \%$ & Réplicas* & Média** & $\mathrm{R} \%$ \\
\hline Staphylococcus aureus & $67 / 61 / 59$ & 62 & $59 / 58 / 65$ & 61 & 98,4 & $57 / 59 / 60$ & 59 & 96,7 \\
\hline Pseudomonas aeruginosa & $45 / 51 / 49$ & 48 & $40 / 42 / 40$ & 41 & 85,4 & $40 / 39 / 44$ & 41 & 85,4 \\
\hline Escherichia coli & $55 / 55 / 59$ & 56 & $51 / 53 / 51$ & 52 & 92,9 & $50 / 53 / 51$ & 51 & 91,1 \\
\hline Candida albicans & $76 / 78 / 73$ & 76 & $74 / 72 / 73$ & 73 & 96,0 & $70 / 71 / 78$ & 73 & 96,0 \\
\hline Aspergillus niger & $34 / 29 / 31$ & 31 & $30 / 33 / 31$ & 31 & 100,0 & $29 / 33 / 31$ & 31 & 96,8 \\
\hline
\end{tabular}

* $\mathrm{N}^{\circ}$ unidades formadoras de colônia (UFC) por placa; ** Média das triplicatas (UFC); R\%: porcentagem de recuperação.

TABELA V - Avaliação da atividade inibitória do produto diluído sobre o crescimento de microrganismos testes em meios adicionados de $4 \%(\mathrm{p} / \mathrm{v})$ de polissorbato 20 e $0,5 \%(\mathrm{p} / \mathrm{v})$ de lecitina de soja

\begin{tabular}{|c|c|c|c|c|c|c|c|c|}
\hline \multirow{3}{*}{ Microrganismos } & \multirow{2}{*}{\multicolumn{2}{|c|}{ Controle* }} & \multirow{2}{*}{\multicolumn{3}{|c|}{$\begin{array}{c}\text { Produto } \\
1: 10\end{array}$}} & \multicolumn{3}{|c|}{ Diluído** } \\
\hline & & & & & & & $1: 100$ & \\
\hline & Réplicas & Média & Réplicas & Média & $\mathrm{R}(\%)$ & Réplicas & Média & $\mathrm{R}(\%)$ \\
\hline$\overline{\text { Staphylococcus aureus }}$ & $87 / 85 / 88$ & 87 & $86 / 87 / 85$ & 86 & 98,8 & $85 / 84 / 83$ & 85 & 98,8 \\
\hline Pseudomonas aeruginosa & $65 / 66 / 65$ & 65 & $63 / 60 / 61$ & 61 & 93,8 & $62 / 61 / 60$ & 61 & 100,0 \\
\hline Escherichia coli & $48 / 43 / 40$ & 44 & $44 / 43 / 43$ & 43 & 97,7 & $42 / 40 / 45$ & 42 & 95,5 \\
\hline Candida albicans & $41 / 43 / 47$ & 44 & $40 / 42 / 42$ & 41 & 93,2 & $45 / 41 / 46$ & 44 & 100,0 \\
\hline Aspergillus niger & $34 / 37 / 31$ & 34 & $33 / 33 / 36$ & 34 & 100,0 & $30 / 35 / 32$ & 32 & 94,1 \\
\hline
\end{tabular}

* Crescimento de microrganismos testes na ausência do Produto (UFC/mL por placa e a média das triplicatas); ** Crescimento de microrganismos testes na presença de $1 \mathrm{~mL}$ de produto diluído (1:10 e 1:100) em solução de cloreto de sódio a $0,85 \%(\mathrm{p} / \mathrm{v})$ acrescida de $4 \%$ de polissorbato $20(\mathrm{p} / \mathrm{v})$ (UFC/mL por placa e a média das triplicatas).

$\mathrm{R}(\%)$ : porcentagem de recuperação.

TABELA VI - Características das colônias de patógenos específicos em meios de isolamento seletivo, após crescimento em meio de enriquecimento não-seletivo adicionado do produto diluído

\begin{tabular}{lcccc}
\hline $\begin{array}{l}\text { Microrganismo } \\
\text { Indicador }\end{array}$ & $\begin{array}{c}\text { Enriquecimento } \\
\text { em meio } \\
\text { não seletivo* }\end{array}$ & $\begin{array}{c}\text { Isolamento em } \\
\text { meio seletivo }\end{array}$ & $\begin{array}{c}\text { Característica } \\
\text { do crescimento } \\
\text { Diluição 1:20 }\end{array}$ & $\begin{array}{c}\text { Característica } \\
\text { do crescimento } \\
\text { Diluição 1:200 }\end{array}$ \\
\hline $\begin{array}{l}\text { Escherichia coli } \\
\text { Pseudomonas aeruginosa }\end{array}$ & caldo lactosado & ágar MacConckey & típico & Típico \\
caldo caseína-soja & ágar Cetrimida & $\begin{array}{c}\text { crescimento } \\
\text { não típico }\end{array}$ & Típico \\
ausência & Típico \\
& caldo caseína-soja & ágar Vogel Johnson & & crescimento
\end{tabular}

\footnotetext{
* adicionaram-se $5 \mathrm{~g}$ do produto homogeneizado em $5 \mathrm{~mL}$ de miristato de isopropila em $90 \mathrm{~mL}$ de caldo caseína-soja e de caldo lactosado acrescidos de 4\% (p/v) de polissorbato 20 e $0,5 \%(\mathrm{p} / \mathrm{v})$ de lecitina de soja (diluição 1:20). Amostras de $10 \mathrm{~mL}$ das diluições 1:20 foram transferidas para $90 \mathrm{~mL}$ dos caldos caseína-soja e lactosado adicionados dos tensoativos.
} 
TABELA VII - Característica do crescimento microbiano nos meios de isolamento seletivo

\begin{tabular}{lll}
\hline Microrganismo Indicador & Isolamento em meio seletivo & Característica do Crescimento \\
\hline Escherichia coli & ágar MacConckey & $\begin{array}{l}\text { Colônias de coloração rosa intensa "pink" } \\
\text { circundadas por zona de bile precipitado }\end{array}$ \\
Pseudomonas aeruginosa & ágar Cetrimida & $\begin{array}{l}\text { Colônias de coloração esverdeada } \\
\text { apresentando fluorescência sob luz UV }\end{array}$ \\
Staphylococcus aureus & ágar Vogel Johnson & $\begin{array}{l}\text { Colônias de coloração preta brilhante } \\
\text { circundada por zona amarela }\end{array}$ \\
\hline
\end{tabular}

cando interferência dos agentes antimicrobianos da formulação na menor diluição avaliada. De forma contrastante, a maior sensibilidade detectada para o ensaio quantitativo (1:10) pode ser decorrente da diluição adicional do produto na placa de petri, quando da adição de aproximadamente $15 \mathrm{~mL}$ de ágar caseína-soja, contendo os inativantes específicos.

\section{CONCLUSÃO}

Os ensaios realizados indicam as condições necessárias para a avaliação da amostra. Com referência ao método de contagem adotado, a diluição 1:10 foi considerada validada. Para a pesquisa dos seguintes microrganismos patogênicos específicos: Escherichia coli, Pseudomonas aeruginosa e Staphylococcus aureus, a diluição 1:200 apresentou condição adequada para o crescimento microbiano e, portanto, válida para o ensaio.

\section{ABSTRACT \\ Validation of method to evaluate sanitary quality of lipophilic base cosmetics}

The validation of method to evaluate the sanitary quality of lipophilic base cosmetics was performed using chemical neutralizers and dilution in order to eliminate the inhibitory effect on the microbial growth. The preparation of the sample was performed aiming the homogeneity in the culture media. Isopropyl miristate was used for the solubilization of the sample and polysorbate 20 was used as surfactant. Besides these substances, it was added to the diluent $0.5 \%(\mathrm{w} / \mathrm{v})$ of soy lecithin to neutralize the antimicrobial activity of the benzalkonium chloride. The purpose of the assays was to demonstrate the lack of inhibitory effect on the microbial growth due to antimicrobial activity of the product as well as of the neutralizing and solubilizing agents and the surfactant used in the assay. With regard to a quantitative evaluation, the results showed a lack of inhibitory effect of the product on the microbial growth in dilutions $1: 10$ and 1:100. The percentage of microbial recovery was at least $93.2 \%$ indicating the validation of the method in accordance with the official criteria adopted. As for the qualitative analysis, in dilution 1:20, it was noticed an inhibitory effect for the following microorganisms: Pseudomonas aeruginosa and Staphylococcus aureus. Since this mentioned effect was not noticed when dilution was 1:200, the latter dilution was considered valid for the assay.

UNITERMS: Validation. Cosmetics. Sanitary quality. Chemical neutralization.

\section{REFERÊNCIAS BIBLIOGRÁFICAS}

BOWMAN, F. W.; KNOLL, E. W.; WHITE, M.; MISLIVEC, P. Survey of microbial contamination of ophthalmic ointments. J. Pharm. Sci., Washington, v.61, n. 4, p. $532-535,1972$.

BRASIL. Leis, Decretos etc. - Resolução ANVS n 481 de 23 de setembro de 1999. Secretaria da Vigilância Sanitária. Diário Oficial da União, Brasília, n.342, 27 de setembro de 1999, seção I, p.29.

BRITISH Pharmacopoeia. London: Her Majesty's Stationery Office, 1980, addendum 1986. appendix XVI, A 104.

BRITISH Pharmacopoeia. London: Her Majesty's Stationery Office, 1988. Appendix XVI B, A 195.

BRITISH Pharmacopoeia. London: Her Majesty's Stationery Office, 1993. Appendix XVI B, A 188.

BRITISH Pharmacopoeia. London: Her Majesty's Stationery Office, 1999. Appendix XVI B, A 255-A259. 
DAVISON, A. L.; HOOPER, W.L.; SPOONER, D.F.; FARWELL, J.A.; BAIRD, R. The validity of the criteria of pharmacopoeial preservative efficacy tests - a pilot study. Pharm. J., London, v.246, n.6634, p.555-557, 1991.

EUROPEAN Pharmacopoeia. 3 ed. Paris.Mainsonneuve, 1996. p.83.

EUROPEAN Pharmacopoeia. 3 ed. Paris. Mainsonneuve, 1996, supplement 1999. p.33

FARMACOPÉIA BRASILEIRA. 4.ed. São Paulo: Atheneu, 1988. p.V.5.1.6-3.

KAVANAUGHE, E.; McEWEN, G.N., eds. The Cosmetic, Toiletries and Fragrance Association (CTFA). Microbiology Guidelines. Washington: CTFA, 1999. n. p.

KOHN, S. R.; GERSHENFELD, L.; BARR, M. Effectiveness of antibacterial agents presently employed in ophthalmic preparations as preservatives against Pseudomonas aeruginosa. J. Pharm. Sci., Washington, v.52, n.10, p.967-974, 1963.

OHARA, M. T.; SAITO, T. Aplicação do cloreto de trifeniltetrazólio no teste de limite microbiano em medicamentos e cosméticos. Técnica de Pour-plate. Rev. Farm. Bioquím. Univ. S. Paulo, São Paulo, v.29, n.2, p.73-80, 1993.

OHARA, M.T.; SAITO, T. Application of triphenyltetrazolium chloride in microbial limit test in pharmaceutical and cosmetics. J. AOAC, Arlington, v.78, n.6, p.1525-1529, 1995.
RINGERTZ, S.; RINGERTZ, O. Antimicrobial effect of isopropil myristate when used as solvent in sterility testing. Pharm. Acta Helv., Zurich, v.57, n.7, p.193-195, 1982.

ROBERTSON, J.H. Sterility testing of ophthalmic ointments using isopropyl myristate. Bull. Parenter. Drug Assoc., Philadelphia, v.28, p.288, 1974.

SINGER, S. The use of preservative neutralizers in diluents and plating media. Cosmet. Toiletries, Oak Park, v.102, n.12, p.55-60, 1987.

THE UNITED States Pharmacopoeia. 12 ed. Easton: Mack , 1942. p.556.

THE UNITED States Pharmacopeoia. 19 ed. Rockville: United States Pharmacopeial Convention, 1975. p.588.

THE UNITED States Pharmacopoeia. 23 ed. Rockville: United States Pharmacopeial Convention, 1995. p.16811682.

THE UNITED States Pharmacopoeia. 24 ed. Rockville: United States Pharmacopeial Convention, 2000. p.18091818.

THE UNITED States Pharmacopoeia. 25 ed. Rockville: United States Pharmacopeial Convention, 2002.p.22592261.

TSUJI, K.; ROBERTSON, J. H. Microcount method for petrolatum-based topical ointment containing waxes. Appl. Microbiol., Washington, v.20, n.5, p.802-804, 1970.

Recebido para publicação em 03 de dezembro de 2002. 